\title{
Sodium Cation Affinities of Commonly Used MALDI Matrices Determined by Guided Ion Beam Tandem Mass Spectrometry
}

\author{
S. D. M. Chinthaka, M. T. Rodgers \\ Department of Chemistry, Wayne State University, Detroit, MI 48202, USA
}

\begin{abstract}
The sodium cation affinities of six commonly used MALDI matrices are determined here using guided ion beam tandem mass spectrometry techniques. The collision-induced dissociation behavior of six sodium cationized MALDI matrices, $\mathrm{Na}^{+}(\mathrm{MALDI})$, with $\mathrm{Xe}$ is studied as a function of kinetic energy. The MALDI matrices examined here include: nicotinic acid, quinoline, 3aminoquinoline, 4-nitroaniline, picolinic acid, and 3-hydroxypicolinic acid. In all cases, the primary dissociation pathway corresponds to endothermic loss of the intact MALDI matrix. The cross section thresholds are interpreted to yield zero and $298 \mathrm{~K} \mathrm{Na}^{+}-\mathrm{MALDI}$ bond dissociation energies (BDEs), or sodium cation affinities, after accounting for the effects of multiple ionneutral collisions, the kinetic and internal energy distributions of the reactants, and dissociation lifetimes. Density functional theory calculations at the B3LYP/6-311+G(2d,2p)//B3LYP/6-31G* and MP2(full)/6-311+G(2d,2p)//B3LYP/6-31G* levels of theory are used to characterized the structures and energetics for these systems. The calculated BDEs exhibit very good agreement with the measured values for most systems. The experimental and theoretical $\mathrm{Na}^{+}-\mathrm{MALDI}$ BDEs determined here are compared with those previously measured by cation transfer equilibrium methods.
\end{abstract}

Key words: Bond dissociation energy, Collision-induced dissociation, Guided ion beam tandem mass spectrometry, MALDI matrices, Sodium cations

\section{Introduction}

$\mathrm{M}$ atrix assisted laser desorption ionization (MALDI) has become a very popular and useful tool for generating gaseous macromolecular ions. These species often decompose at their melting points, leading to decomposition upon vaporization and ionization by classical gas-phase ionization techniques. MALDI has been specifically developed for the analysis of fragile biomolecules such as proteins, nucleic acids, and carbohydrates typically as singly charged ions.

Electronic supplementary material The online version of this article (doi:10.1007/s13361-012-0336-8) contains supplementary material, which is available to authorized users.

Correspondence to: M. T. Rodgers; e-mail: mrodgers@chem.wayne.edu
MALDI is also widely used for the analysis of syntactic polymers [1-12] and has also been successfully employed for the analyses of other macromolecules such as fullerenes [13], carbon nanotubes [14], and dendrimers [15-17]. Because a large number of experimental parameters influence the ionization processes that occur in MALDI, the ionization mechanisms and kinetics are not fully understood despite its widespread usage and popularity. In an attempt to better understand and control MALDI, several groups have focused on studies directed at elucidating the mechanisms that lead to MALDI [18-24]. The proposed mechanisms are based on empirical observations, but thus far no single mechanism has been proposed that is able to explain all of the experimental observations. The lack of thermodynamic, kinetic, and structural information has impeded elucidation of the MALDI ionization mechanism(s). Because of this 
dearth of information, no rational approach has been developed for matrix selection and, thus, it is still often achieved by trial and error.

Cationization by alkali metal cations such as $\mathrm{Na}^{+}$and $\mathrm{K}^{+}$is one of the secondary ionization processes that occur in MALDI [25-33]. Cationization is also believed to influence protonation, deprotonation, and electron transfer ionization processes that occur in MALDI. Alkali metal cations are ubiquitous and generally arise from purification procedures, impurities in the matrix and analyte, or from the glassware employed. In MALDI analyses, cationization is almost always observed in biomolecular analyses and has been virtually the only ionization pathway available for polymer analyses [1, 3, 9]. Such cationization is problematic in many instances. Cationization often deteriorates the quality of MALDI spectra by distributing the total ion current over protonated, cationized, and metal cation clustered signals. This complicates the interpretation of the data and prevents rapid identification of compounds in complex mixtures. Therefore, methods for preventing cationization are paramount to the optimization of many MALDI analyses. In contrast, cationization assists ionization of analytes that are difficult to ionize by other ionization pathways. Therefore, salts of metal cations such as $\mathrm{Li}^{+}, \mathrm{Cu}^{2+}$, and $\mathrm{Ag}^{+}$are often added to MALDI samples to enhance signal or suppress cationization by $\mathrm{Na}^{+}$and $\mathrm{K}^{+}[31$, $34,35]$. Several other mechanical methods, including a postcrystallization wash [36] layered deposition of matrix and analyte [37], and the use of liquid matrices (ionic liquids containing matrix anions) [38], have also been proposed and tested to minimize cationization in MALDI.

Based on previous studies, ion formation in MALDI is believed to occur both in the condensed phase matrix-analyte crystal prior to laser ablation and in the gas phase after laser ablation. Incorporation of the analyte into the matrix crystal lattice is believed to be a prerequisite for a successful MALDI analysis, especially when the dried droplet sample preparation technique is used [22]. Thereafter, laser ablation brings the analyte and matrix into the gas phase. However, most ionization including cationization is believed to occur in the gas phase [39]. Although MALDI ionization mechanisms are not fully understood, there exists strong experimental evidence that secondary ionization processes occur in the laser plume and are responsible for metal-ligand exchanges [21, 40, 41]. Sodiated analytes are believed to come from sodium cation transfer reactions that occur in the gas phase [42]. Gas phase cationization could be a relatively controllable process, and be employed to optimize MALDI analyses if the relevant gas phase thermodynamic and kinetic information become available. Limited theoretical and experimental studies of the gas phase properties of MALDI matrices have been reported in the literature. These studies have focused on determining the gas phase proton affinities [43-46], basicities/acidities [47-50], and ionization energies of MALDI matrices [43]. Very few studies have reported cation affinities [51-55] of MALDI matrices. In addition, the reliability of some of the values measured by cation transfer equilibria and reaction kinetics that have been reported [51, 52] has been shown to be questionable [54]. Therefore, it is important to determine accurate absolute gas-phase sodium cation affinities of MALDI matrices to allow optimization of MALDI analyses and enhance our current understanding of MALDI ionization processes. Such accurate thermodynamic data is needed to develop models for selecting an appropriate matrix for a particular analyte. Such thermodynamic data is important for minimizing the adverse effects and maximizing the advantages of cationization. However, the thermodynamic data currently available are too limited to allow a priori optimization of MALDI analyses.

In previous work, we determined the sodium and potassium cation affinities and stable binding conformations of $\mathrm{Na}^{+}$and $\mathrm{K}^{+}$ with benzoic acid and all of the mono- and dihydroxy substituted benzoic acids, several of which have been used extensively as MALDI matrices $[54,55]$. In this study, we expand this work to determine the sodium cation affinities and stable binding conformations of $\mathrm{Na}^{+}$to six additional commonly used MALDI matrices. The sodium cation affinities are determined using guided ion beam tandem mass spectrometry techniques, while theoretical electronic structure calculations are performed to characterize the structures and provide theoretical estimates for the sodium cation affinities. The MALDI matrices examined include nicotinic acid (NA), quinoline (Q), 3-aminoquinoline (AQ), 4-nitroaniline (PNA), picolinic acid (PA), and 3-hydroxypicolinic acid, (HPA). The structures of these MALDI matrices along with their calculated dipole moments and isotropic molecular polarizabilities are shown in Figure 1. The kinetic energy dependent cross sections for collision-induced dissociation (CID) processes are analyzed using methods developed previously. The internal and trans-
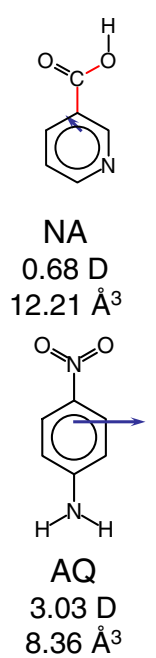

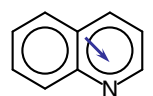

Q

$2.11 \mathrm{D}$ $16.71 \AA^{3}$

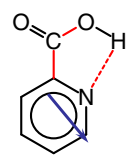

PA

$5.83 \mathrm{D}$

$2.09 \AA^{3}$
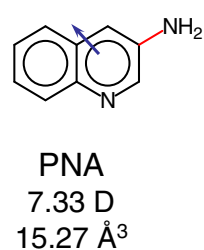

$15.27 \AA^{3}$

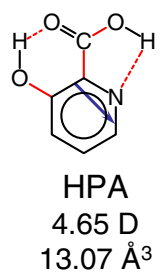

Figure 1. Structures of the MALDI matrices. Properly scaled dipole moments in Debye are shown as arrows. PBE0/6-311+G(2d,2p) molecular polarizabilities in $\AA^{3}$ are also shown. The dipole moments and polarizabilities are taken from theoretical calculations performed here. Bonds indicated in red correspond to those about which the various functional groups can be rotated to produce different stable conformations of the MALDI matrices 
lational energy distribution of the reactants, multiple ionneutral collisions, and the kinetics of unimolecular dissociation are explicitly included in the analysis. Bond dissociation energies (BDEs) of six $\mathrm{Na}^{+}$(MALDI) complexes are derived and compared with values determined from ab initio and density functional theory. Comparison is also made to values previously determined via sodium cation transfer equilibria.

\section{Experimental}

\section{General Procedures}

Cross sections for CID of six $\mathrm{Na}^{+}$(MALDI) complexes with $\mathrm{Xe}$, where MALDI=NA, Q, AQ, PNA, PA, and HPA were measured as a function of kinetic energy using a guided ion beam tandem mass spectrometer that has been described previously [56]. Sodium cations are generated by glow discharge via $\mathrm{Ar}^{+}$sputtering of a tantalum or iron boat containing sodium metal operated at $\sim 2-4 \mathrm{kV}$ and $\sim 15$ $-30 \mathrm{~mA}$. The $\mathrm{Na}^{+}$(MALDI) complexes are formed by condensation of $\mathrm{Na}^{+}$and the neutral MALDI matrix in a $1.2 \mathrm{~m}$ long flow tube operating at $0.5-0.7$ Torr pressure. All of the MALDI matrices examined here are solids except quinoline, which is a liquid. The solids are introduced into the flow tube by thermal vaporization, while liquid matrices are introduced using a needle leak valve. The $\mathrm{Na}^{+}$(MALDI) complexes are collisionally stabilized and thermalized by $>10^{5}$ collisions with the $\mathrm{He}$ and Ar bath gases, such that ions emerging from the source region have internal energies that are well described by a Maxwell-Boltzmann distribution of rovibrational states at room temperature.

The ions are effusively sampled, focused, accelerated, and focused into a magnetic sector momentum analyzer for reactant ion selection. Mass-selected ions are decelerated to a desired kinetic energy and focused to an octopole ion beam guide. The octopole passes through a static gas cell containing Xe at low pressure $(0.05-0.20 \mathrm{mTorr})$ to ensure that multiple ion-neutral collisions are improbable. The octopole ion guide also acts as an efficient radial trap for ions such that scattered reactant and products ions are not lost as they drift toward the end of the octopole [57-59]. The product and unreacted beam ions are focused into a quadrupole mass filter for mass analysis and subsequently detected with a secondary electron scintillation (Daly) detector and standard pulse counting techniques.

\section{Data Handling}

The measured ion intensities are converted to absolute cross sections using a Beers' law analysis as described previously $[60,61]$. Absolute uncertainties in the cross section magnitudes are estimated to be $\pm 20 \%$, which are derived largely from errors in the pressure measurement and the effective length of the interaction region. Relative uncertainties are approximately $\pm 5 \%$.

Ion kinetic energies in the laboratory frame, $E_{\text {lab }}$, are converted to energies in the center-of-mass frame, $E_{\mathrm{CM}}$, using the formula $E_{\mathrm{CM}}=E_{\mathrm{lab}} m /(m+M)$, where $M$ and $m$ are the masses of the $\mathrm{Na}^{+}$(MALDI) and Xe reactants, respectively. All energies reported here are in the center-of-mass frame unless otherwise noted. The absolute zero and distribution of the $\mathrm{Na}^{+}$(MALDI) kinetic energies are determined using the octopole ion guide as a retarding potential analyzer as previously described [60]. The distribution of ion kinetic energies is nearly Gaussian with a full width at half-maximum (FWHM) between 0.2 and $0.4 \mathrm{eV}(\mathrm{lab})$ for these experiments. The uncertainty in the absolute energy scale is $\pm 0.05 \mathrm{eV}$ (lab).

Because multiple collisions can influence the shape of CID cross sections, and the threshold regions are most sensitive to these effects, each CID cross section was measured twice at three nominal Xe pressures $(0.05,0.10$, and $0.20 \mathrm{mTorr}$ ). Data free from pressure effects are obtained by extrapolating to zero pressure of the neutral Xe reactant as previously described [62, 63]. Thus, cross sections subjected to thermochemical analysis are the result of single bimolecular encounters.

\section{Theoretical Calculations}

To obtain model structures, vibrational frequencies, rotational constants, and energetics for the neutral MALDI matrices and their complexes to $\mathrm{Na}^{+}$, ab initio and density functional theory calculations were performed using the Gaussian 03 suite of programs [64]. Geometry optimizations were performed at the B3LYP/6-31 G* level of theory. The optimized structures were used to calculate the vibrational frequencies and rotational constants necessary for modeling of the experimental data. The vibrational frequencies were scaled by a factor of 0.9804 for thermal energy adjustments and thermochemical modeling of experimental data [65]. The scaled vibrational frequencies are listed in the Supplementary Information in Table $1 \mathrm{~S}$, while the rotational constants are given in Table 2S. Single point energy calculations were performed at the B3LYP/6-311+G(2d,2p) and MP2(full)/6-311+G(2d,2p) levels of theory using the B3LYP/6-31 G* optimized geometries. Zero point energy (ZPE) and basis set superposition error (BSSE) corrections were also included. As a result of the multiple orientations possible for the various functional groups present as well as the multiple favorable $\mathrm{Na}^{+}$binding sites to these MALDI matrices, multiple low-energy conformations of these species are possible. Therefore, we carefully consider all possible conformations of the MALDI matrices and $\mathrm{Na}^{+}$(MALDI) complexes to determine the relative stabilities and the groundstate conformations of these species. This is achieved by determining all of the stable orientations for each functional group within the MALDI matrices, and then examining all possible combinations of the stable orientations of the various functional groups present. The bonds through which the various functional groups can be rotated are shown in Figure 1.

Polarizability is one of the factors that contribute to the strength of noncovalent interactions. The isotropic molecular 
polarizabilities of the ground-state conformations of the neutral MALDI matrices were calculated based on a dipole electric field and carried out using the PBE0 hybrid functional and the $6-311+\mathrm{G}(2 \mathrm{~d}, 2 \mathrm{p})$ basis set using the B3LYP/6-31 G* optimized geometries [66]. This level of theory was chosen because polarizabilities determined using the PBE0 functional exhibit better agreement with experimentally determined polarizabilities than values computed using the B3LYP functional employed for determining the structures and energetics of these MALDI matrices [67].

\section{Thermochemical Analysis}

The CID cross sections are modeled using an empirical threshold energy law, Equation (1),

$$
\sigma(E)=\sigma_{0} \sum_{i} g_{i}\left(E+E_{i}-E_{0}\right)^{n} / E
$$

where $\sigma_{0}$ is an energy independent scaling factor, $E$ is the relative translational energy of the reactants, $E_{0}$ is the threshold for reaction of the ground electronic and rovibrational state, and $n$ is an adjustable parameter that describes the efficiency of kinetic to internal energy transfer [68]. The summation is over the ro-vibrational states of the reactant ions, $i$, where $E_{i}$ is the excitation energy of each rovibrational state, and $g_{i}$ is the relative population of each state $\left(\sum g_{i}=1\right)$. The relative reactivity of all ro-vibrational states, as reflected by $\sigma_{0}$ and $n$, is assumed to be equivalent.

The Beyer-Swinehart algorithm [69-71] is used to evaluate the density of the ro-vibrational states and the relative populations, $g_{i}$, are calculated for a MaxwellBoltzmann distribution at $298 \mathrm{~K}$, the internal temperature of the reactants. The average internal energy of the groundstate conformations of the neutral MALDI matrices and $\mathrm{Na}^{+}$(MALDI) complexes are also included in the Supplementary Information, Table 1S. To account for the inaccuracies in the computed frequencies, we have scaled the frequencies (prescaled by 0.9804 ) by $\pm 10 \%$. The corresponding change in the average vibrational energy is taken to be an estimate of one standard deviation of the uncertainty in the vibrational energy (Table 1S).

Statistical theories for unimolecular dissociation, specifically Rice-Ramsperger-Kassel-Marcus (RRKM) theory of the collisionally-activated ions are also included in a modified form of Equation (1) to account for the possibility that these ions may not have undergone dissociation prior to arriving at the detector $\left(\sim 10^{-4} \mathrm{~s}\right)$ as described in detail elsewhere [72, 73]. In our analyses, we assume that the transition states (TSs) are loose and product-like because the interactions between $\mathrm{Na}^{+}$ and the MALDI matrices are largely electrostatic. The best model for the TS of such electrostatically bound complexes is a loose phase space limit (PSL) model located at the centrifugal barrier for the interaction of $\mathrm{Na}^{+}$with the MALDI matrix as described in detail elsewhere [72]. The parameters appropriate for the PSL TS are the frequencies and rotational constants of the products. The ro-vibrational frequencies for the energized molecules and the TSs leading to dissociation are given in the Supplementary Information in Tables $1 \mathrm{~S}$ and 2S.

The model represented by Equation (1) is expected to be appropriate for translationally driven reactions [74], and has been found to reproduce CID cross sections well. The model of Equation (1) is convoluted with the kinetic energy distributions of both the reactant $\mathrm{Na}^{+}$(MALDI) complex and neutral Xe atom, and a nonlinear least-squares analysis of the data is performed to give optimized values for the parameters $\sigma_{0}, E_{0}$, or $E_{0}(\mathrm{PSL})$, and $n$. The error associated with the measurement of $E_{0}$ and $E_{0}(\mathrm{PSL})$ is estimated from the range of threshold values determined for the zero-pressure-extrapolated data sets, variations associated with uncertainties in the vibrational frequencies (scaling as discussed above), and the error in the absolute energy scale, $\pm 0.05 \mathrm{eV}$ (lab). For analyses that include the RRKM lifetime analysis, the uncertainties in the reported $E_{0}(\mathrm{PSL})$ values also include the effects of increasing and decreasing the time assumed available for dissociation $\left(\sim 10^{-4} \mathrm{~s}\right)$ by a factor of 2 .

Equation (1) explicitly includes the internal energy of the reactant ion, $E_{i}$. All energy available is treated statistically because the internal energy of the reactants is redistributed throughout the accessible ro-vibrational energy states of the $\mathrm{Na}^{+}$(MALDI) complex upon collision with Xe. The threshold energies, $E_{0}(\mathrm{PSL})$, obtained from these analyses can be equated to $0 \mathrm{~K}$ BDEs or sodium cation affinities because the CID processes examined here are simple noncovalent bond fission reactions $[75,76]$.

\section{Results}

\section{Cross Sections for Collision-Induced Dissociation}

Experimental cross sections were obtained for the interaction of Xe with six $\mathrm{Na}^{+}(\mathrm{MALDI})$ complexes, where MALDI= nicotinic acid (NA), quinoline $(\mathrm{Q}), 3$-aminoquinoline (AQ), 4-nitroaniline (PNA), picolinic acid (PA), and 3-hydroxypicolinic acid (HPA). Figure 2a shows representative data for the $\mathrm{Na}^{+}(\mathrm{NA})$ complex. The other $\mathrm{Na}^{+}$(MALDI) complexes exhibit similar behavior and are included in the Supplementary Information as Figure 1S. Loss of the intact MALDI matrix is the only CID pathway observed for all six complexes, CID reactions 2 .

$$
\mathrm{Na}^{+}(\mathrm{MALDI})+\mathrm{Xe} \rightarrow \mathrm{Na}^{+}+\mathrm{MALDI}+\mathrm{Xe}
$$

The CID cross sections exhibit an apparent threshold for $\mathrm{Na}^{+}$production in the range from 0.5 to $1.5 \mathrm{eV}$, while the maximum cross section magnitudes are in the range from 2 to $12 \AA^{2}$. Ligand exchange to form $\mathrm{Na}^{+} \mathrm{Xe}$ was also observed as very minor reaction pathway in the $\mathrm{Na}^{+}(\mathrm{NA})$ system, reaction 3 .

$$
\mathrm{Na}^{+}(\mathrm{NA})+\mathrm{Xe} \rightarrow \mathrm{Na}^{+} \mathrm{Xe}+\mathrm{NA}
$$



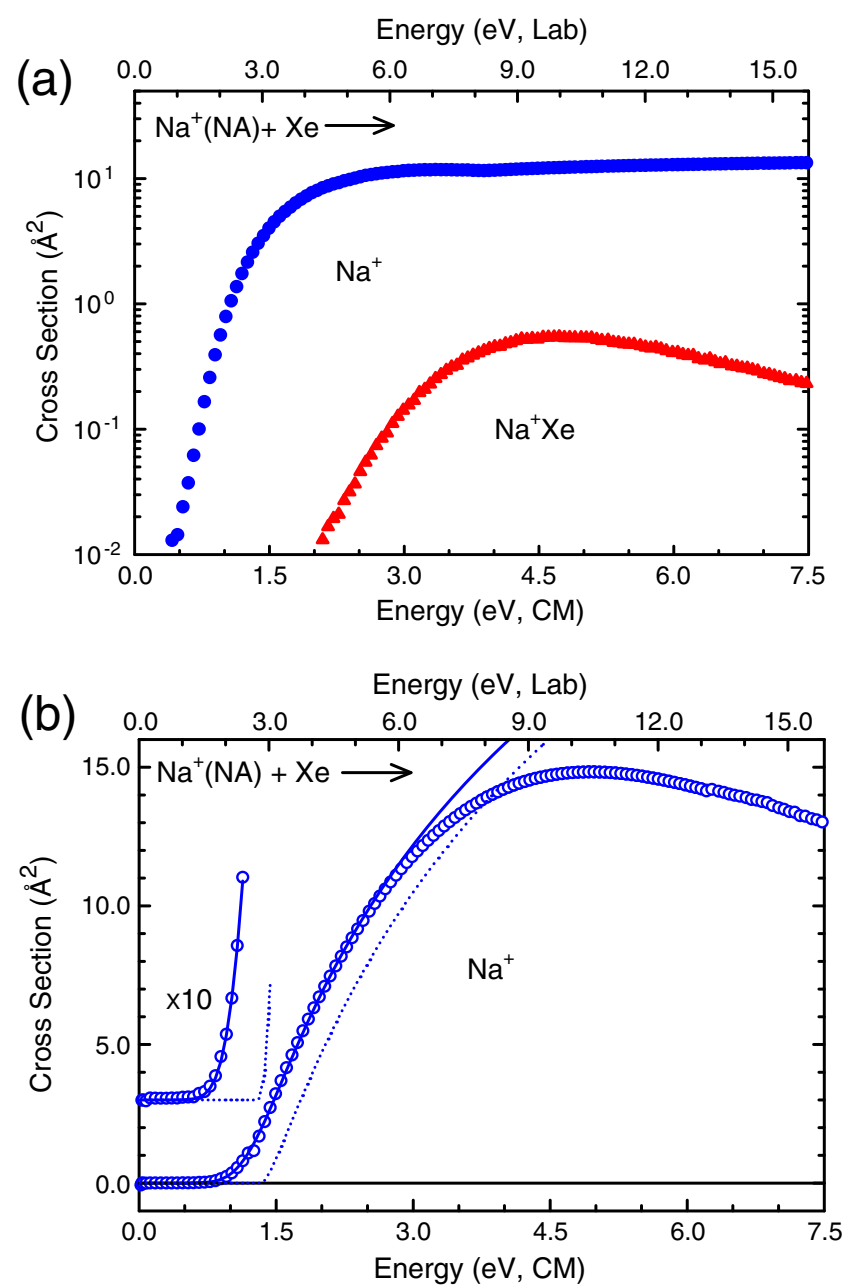

Figure 2. Cross section for $\mathrm{CID}$ of $\mathrm{Na}^{+}(\mathrm{NA})$ with $\mathrm{Xe}$ as a function of kinetic energy in the center-of-mass frame (lower $x$-axis) and the laboratory frame (upper $x$-axis). Data are shown for a Xe pressure of $\sim 0.2$ mTorr (a). Zero-pressureextrapolated cross section for $\mathrm{CID}$ of $\mathrm{Na}^{+}(\mathrm{NA})$ with $\mathrm{Xe}$ in the threshold region as a function of kinetic energy in the center of mass frame (lower $x$-axis) and the laboratory frame (upper $x$-axis). The solid line shows the best fit to the data using the model of Equation (1) convoluted over the neutral and ion kinetic and internal energy distributions. The dotted line shows the model cross section in the absence of experimental kinetic energy broadening for reactants with an internal temperature of $0 \mathrm{~K}$ (b)
It is likely that this process occurs for all systems, but was minor enough that the $\mathrm{Na}^{+} \mathrm{Xe}$ ligand exchange product could not be differentiated from noise in the other systems.

\section{Threshold Analysis}

The model of Equation (1) was used to analyze the thresholds for CID reactions 2 of six $\mathrm{Na}^{+}$(MALDI) complexes. The results of these analyses are provided in Table 1 and representative results for the $\mathrm{Na}^{+}$(NA) complex are shown in Figure 2b. The analyses for the other $\mathrm{Na}^{+}$(MALDI) complexes are shown in the Supplementary Information, Figure 2S. In all cases, the experimental cross sections are accurately reproduced using a loose PSL TS model [72]. Previous work has shown that this model provides the most accurate assessment of the kinetic shifts for CID of electrostatically bound ion-molecule complexes $[72,77]$. Good reproduction of data is obtained over energy ranges exceeding $2.5 \mathrm{eV}$ and cross section magnitudes of at least a factor of 100. Table 1 also includes threshold values, $E_{0}$, obtained without inclusion of the RRKM lifetime analysis. Comparison of these results with the $E_{0}(\mathrm{PSL})$ values provides a measure of the kinetic shift associated with the finite experimental time window. The observed kinetic shifts should correlate with the density of states at threshold, which depends both on size (or the number of ro-vibrational degrees of freedom available to the system) and the strength of binding. The observed kinetic shifts vary between 0.05 and $1.62 \mathrm{eV}$ across these systems, and generally increase with the size and the BDE of the complex. However, no simple correlation across the entire matrix set is observed as a result of the diversity in the size and modes of $\mathrm{Na}^{+}$binding to these MALDI matrices.

The entropy of activation, $\Delta S^{\dagger}$ is a measure of the looseness of the TS and also a reflection of the complexity of the system. $\Delta S^{\dagger}$ is largely determined by the molecular parameters used to model the energized molecule and TS for dissociation, but also depends on the threshold energy. The $\Delta S^{\dagger}$ (PSL) values at $1000 \mathrm{~K}$ are listed in Table 1 and vary from 18.5 to $36.3 \mathrm{~J} / \mathrm{K} \mathrm{mol}$ across these systems. These values are indicative of a loose TS as expected based upon the PSL TS model employed here.

Table 1. Modeling Parameters of Equation (1), Threshold Dissociation Energies at $0 \mathrm{~K}$, and Entropies of Activation at $1000 \mathrm{~K}$ of Na ${ }^{+}(\mathrm{MALDI}) \mathrm{Complexes}^{\mathrm{a}}$

\begin{tabular}{|c|c|c|c|c|c|c|}
\hline \multirow[t]{2}{*}{ Reactant ion } & $\sigma_{0}{ }^{b}$ & $n^{\mathrm{b}}$ & $E_{0}{ }^{\mathrm{c}}$ & $E_{0}(\mathrm{PSL})^{\mathrm{b}}$ & Kinetic Shift & $\Delta \mathrm{S}^{\dagger}(\mathrm{PSL})^{\mathrm{b}}$ \\
\hline & $(\mathrm{eV})$ & $(\mathrm{eV})$ & $(\mathrm{eV})$ & $(\mathrm{eV})$ & $(\mathrm{eV})$ & $\left(\mathrm{J} \mathrm{mol}^{-1} \mathrm{~K}^{-1}\right)$ \\
\hline $\mathrm{Na}^{+}(\mathrm{NA})$ & $16.3(1.3)$ & $1.11(0.03)$ & $1.37(0.03)$ & $1.29(0.03)$ & 0.08 & $18.5(2.1)$ \\
\hline $\mathrm{Na}^{+}(\mathrm{Q})$ & $14.8(1.7)$ & $0.93(0.03)$ & $1.63(0.04)$ & $1.47(0.04)$ & 0.16 & $28.0(2.3)$ \\
\hline $\mathrm{Na}^{+}(\mathrm{AQ})$ & $4.0(0.4)$ & $1.02(0.06)$ & $1.91(0.04)$ & $1.52(0.06)$ & 0.39 & $19.0(2.0)$ \\
\hline $\mathrm{Na}^{+}$(PNA) & $20.4(3.6)$ & $1.06(0.01)$ & $2.11(0.04)$ & $1.67(0.05)$ & 0.44 & $19.7(2.0)$ \\
\hline $\mathrm{Na}^{+}(\mathrm{HPA})$ & $2.8(0.4)$ & $1.33(0.07)$ & $2.11(0.07)$ & $1.76(0.06)$ & 0.35 & $30.0(2.1)$ \\
\hline $\mathrm{Na}^{+}(\mathrm{PA})$ & $0.9(0.1)$ & $1.37(0.04)$ & $2.06(0.04)$ & $1.80(0.05)$ & 0.26 & $36.3(2.1)$ \\
\hline
\end{tabular}

\footnotetext{
${ }^{a}$ Uncertainties are listed in parentheses.

${ }^{\mathrm{b}}$ Average values for loose PSL transition state.

${ }^{\mathrm{c}}$ No RRKM analysis.
} 


\section{Theoretical Results}

Theoretical structures for the neutral MALDI matrices and $\mathrm{Na}^{+}$(MALDI) complexes as well as theoretical BDEs for the $\mathrm{Na}^{+}$(MALDI) complexes were calculated as described in the Theoretical Calculations section. Schematic representations of the ground-state conformations determined for the MALDI matrices and their calculated dipole moments and isotropic molecular polarizabilities are shown in Figure 1. The B3LYP/6-31G* optimized geometries of the ground-state and stable low-energy conformations of the neutral MALDI matrices are shown in Figure 3S. The ground-state conformations for the $\mathrm{Na}^{+}$(MALDI) complexes are shown in Figure 3, and are compared with other stable low-energy conformations in Figure 4S. In all the cases, the ground-state structures of the neutral MALDI matrices are nearly planar. Only the hydrogen atoms of the amino groups of AQ and PNA lie out of the plane of the molecule in their ground-state conformations. These MALDI matrices can be roughly categorized into two groups; matrices possessing a carboxylic acid moiety and those without one. For the matrices with a carboxylic moiety, the carboxyl hydrogen atom is oriented away from the aromatic ring when intramolecular hydrogen bonds to the carboxylic acid moiety are not possible. Intramolecular hydrogen bonds provide enhanced stability and are present in the ground-state conformations of all MALDI matrices where hydrogen bond donor and acceptor groups/atoms are in close proximity. When hydrogen bonds are possible, the carboxyl hydrogen atom is oriented toward the aromatic ring to allow hydrogen bond formation. Such hydrogen bonding is observed in the groundstate structures of PA and HPA.

\section{Neutral MALDI Matrices}

The geometry optimized structures, calculated dipole moments, and relative stabilities (including ZPE corrections) of all stable conformers of the neutral MALDI matrices are provided in the Supplementary Information in Figure 3S. All possible conformations of the neutral MALDI matrices are considered. As a result of the structural variations among the MALDI matrices studied, each MALDI matrix is discussed separately. Comparisons across the various MALDI matrices are made when appropriate.

The orientations of the various functional groups influence the stability of the neutral MALDI matrix as well as the $\mathrm{Na}^{+}$(MALDI) complex. The bonds denoted in red in the ground-state conformations of the neutral matrices (Figure 1) can rotate to produce different conformers. When these rotations do not form any interactions with other functional groups (i.e., a hydrogen bond) the change in stability is typically small or negligible. In contrast, if these rotations allow interaction with nearby groups, the stability of the matrix is significantly altered. For example, rotation of the carboxyl group in PA produces a significant change in stability compared with the ground-state conformer, as this rotation breaks a hydrogen bond and leads to a repulsive interaction with the ortho hydrogen atom.

\section{Quinoline and 3-Aminoquinoline}

Only one stable conformation of Q (1-azanaphthalene) and AQ (3-amino-1-azanaphthalene) is found as a result of the structural rigidity of the extended $\pi$ networks of these

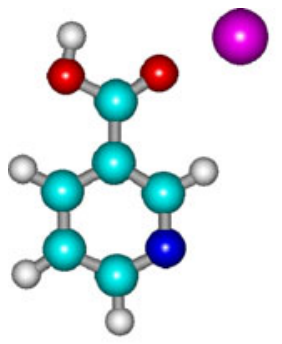

$\mathrm{Na}^{+}(\mathrm{NA})$

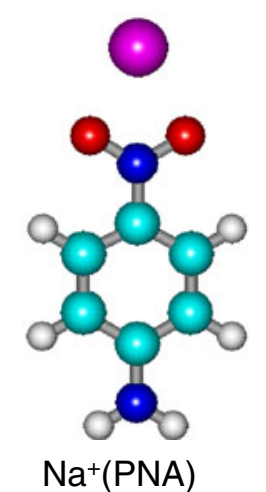

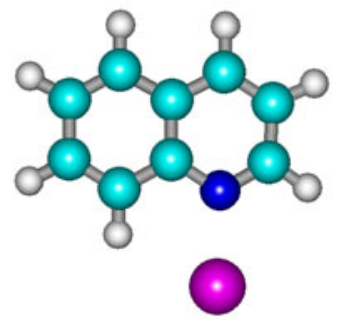

$\mathrm{Na}^{+}(\mathrm{Q})$

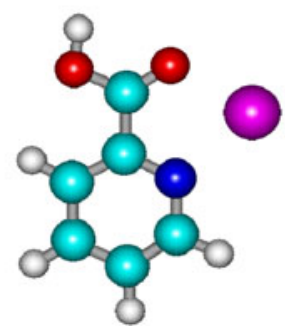

$\mathrm{Na}^{+}(\mathrm{PA})$

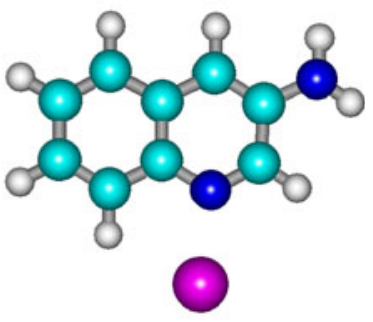

$\mathrm{Na}^{+}(\mathrm{AQ})$

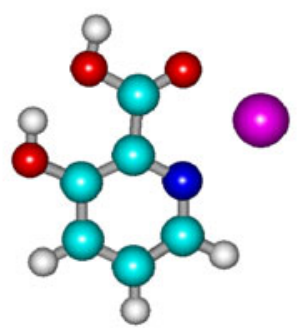

$\mathrm{Na}^{+}(\mathrm{HPA})$

Figure 3. Ground state geometries of the $\mathrm{Na}^{+}(\mathrm{MALDI})$ complexes optimized at the B3LYP/6-31 $\mathrm{G}^{*}$ level of theory 
matrices (Supplementary Information, Figure 3S). Delocalization of the lone pair of the amino nitrogen atom of AQ into the $\pi$ system leads to partial double bond character in the $\mathrm{C}-\mathrm{NH}_{2}$ bond. Rotation about the $\mathrm{C}-\mathrm{NH}_{2}$ bond by $180^{\circ}$ produces an equivalent conformer. The TS for interconversion of these equivalent conformers lies $20.7 \mathrm{~kJ} / \mathrm{mol}$ higher in energy, indicating only modest delocalization of the amino group into the $\pi$ system.

\section{Paranitroaniline}

Only one stable conformer of PNA (1-amino-4-nitrobenzene) is found (Supplementary Information Figure $3 \mathrm{~S}$ ). Both the amino and nitro groups lie in the plane of the aromatic ring and gain additional stabilization via resonance delocalization into the $\pi$ system of the aromatic ring.

\section{Nicotinic Acid}

Four stable conformations of NA (pyridine-3-carboxylic acid) are found as a result of the conformational flexibility of the carboxylic acid moiety and the position of the pyridyl nitrogen atom in the aromatic ring (Supplementary Information, Figure 3S.). As found for the hydroxy-substituted benzoic acids [54], the hydroxyl group of the carboxylic acid moiety is oriented away from the phenyl ring in the groundstate conformation of NA. The presence of the $\mathrm{N}$ atom in the ring leads to two possible conformers, the one having the hydroxyl group on the same side of the ring as the pyridyl $\mathrm{N}$ atom corresponds to the ground state as this conformation minimizes the dipole moment of NA, 0.68 D. Rotation about the $\mathrm{C}-\mathrm{CO}_{2} \mathrm{H}$ bond of the carboxylic acid moiety produces another low-energy conformer $(1.1 \mathrm{~kJ} / \mathrm{mol}$ relative to the ground-state conformer), but the dipole moment is much larger, $3.41 \mathrm{D}$. Alternatively, the hydrogen atom of the carboxylic acid moiety could point toward the phenyl ring. As found for the hydroxy-substituted benzoic acids [54], such conformers are generally much higher in energy, 26.5 and $29.3 \mathrm{~kJ} / \mathrm{mol}$, and have relatively larger dipole moments of 3.20 and 5.24 D, respectively (Supplementary Information, Figure 3S). The loss in stability for the latter conformers arises from steric repulsion between the carboxyl hydrogen atom and the ortho hydrogen atom of the phenyl ring, which causes the carboxylic acid moiety to rotate out of the plane. This rotation leads to a reduction in the stability gained via resonance delocalization of the carbonyl $\pi$ electrons into the $\pi$ system of the aromatic ring.

\section{Picolinic Acid}

Four stable conformations of PA (pyridine-2-carboxylic acid) are found as a result of the conformational flexibility of the carboxylic acid moiety and the position of the pyridyl nitrogen atom in the aromatic ring (Supplementary Information, Figure 3S.). The proximity of the pyridyl nitrogen atom to the carboxylic acid moiety allows a weak hydrogen bonding interaction to be formed between the carboxyl hydrogen and the pyridyl nitrogen atoms, thus favoring this conformation over all others. Rotation about the $\mathrm{C}-\mathrm{OH}$ bond of the carboxylic acid moiety breaks this hydrogen bonding interaction and produces another conformer that is $13.6 \mathrm{~kJ} / \mathrm{mol}$ less stable. Alternatively, the hydrogen bonding interaction could be broken via rotation about the $\mathrm{C}-\mathrm{CO}_{2} \mathrm{H}$ bond. In this case, the resulting conformer is less stable by $46.1 \mathrm{~kJ} / \mathrm{mol}$ as a result of loss of both the hydrogen bonding interaction and resonance delocalization of the carbonyl $\pi$ electrons into the $\pi$ system of the aromatic ring. The fourth conformer can be derived from either of these two latter conformers via rotation about the $\mathrm{C}-\mathrm{CO}_{2} \mathrm{H}$ bond of the former, or about the $\mathrm{C}-\mathrm{OH}$ bond of the latter, and lies $19.5 \mathrm{~kJ} / \mathrm{mol}$ in energy above the ground-state conformation.

\section{3-Hydroxypicolinic Acid}

Seven stable conformations of HPA (3-hydroxypyridine-2carboxylic acid) are found as a result of the conformational flexibility of the carboxylic acid and hydroxyl moieties, and the position of the pyridyl nitrogen atom in the aromatic ring (Supplementary Information, Figure 3S). As found for PA, the proximity of the pyridyl nitrogen atom to the carboxylic acid moiety allows a weak hydrogen bonding interaction to be formed between the carboxyl hydrogen and the pyridyl nitrogen atoms. The presence and location of the hydroxyl group allows a second hydrogen bonding interaction to occur between the carbonyl oxygen and the hydroxyl hydrogen atoms. These hydrogen-bonding interactions confer significant stability and thus favor this conformation over the others. Rotation about the $\mathrm{C}-\mathrm{OH}$ bond of the carboxylic acid moiety breaks the hydrogen bonding interaction between the pyridyl nitrogen and carboxylic acid hydrogen atoms and produces another conformer that is $16.6 \mathrm{~kJ} / \mathrm{mol}$ less stable. Alternatively, the hydrogen bonding interaction between the carbonyl oxygen and the hydroxyl hydrogen atom could be broken via rotation about the $\mathrm{C}-\mathrm{OH}$ bond of the hydroxyl group, in this case the resulting conformer is $49.9 \mathrm{~kJ} / \mathrm{mol}$ higher in energy than the ground-state conformer. The remaining conformations are also much less stable than the ground-state conformer, by 38.8 to $70 \mathrm{~kJ} / \mathrm{mol}$ (Supplementary Information, Figure $3 \mathrm{~S}$ ) as they either involve a single weak hydrogen bonding interaction between the two hydroxyl groups, or are not stabilized by any hydrogen bonding interactions such that the lone pairs of electrons on the adjacent functional groups are oriented toward each other and interact in a repulsive manner.

\section{$\mathrm{Na}^{+}(\mathrm{MALDI})$ Complexes}

The ground-state conformations of the $\mathrm{Na}^{+}$(MALDI) complexes are shown in Figure 3. The neutral MALDI matrices possessing a carboxylic acid moiety undergo a change in conformation to achieve optimal binding to $\mathrm{Na}^{+}$(compare Figures 1 and 3). The structures of all low-energy conformers 
of the $\mathrm{Na}^{+}$(MALDI) complexes that might be expected to be populated under our experimental conditions ( $298 \mathrm{~K}$ internal energy distribution and therefore within $10 \mathrm{~kJ} / \mathrm{mol}$ of the ground-state structure) and their B3LYP/6-311 G(2d,2p) relative stabilities are also provided in the Supplementary Information in Figure 4S. Theoretical BDEs for the groundstate and low-energy conformers of the $\mathrm{Na}^{+}$(MALDI) complexes calculated at the $\mathrm{B} 3 \mathrm{LYP} / 6311+\mathrm{G}(2 \mathrm{~d}, 2 \mathrm{p})$ and MP2 (full)/6-311+G(2d,2p) levels of theory are summarized along with the measured values in Table 2.

\section{$\mathrm{Na}^{+}$(Nicotinic Acid)}

The calculations find three favorable binding modes for $\mathrm{Na}^{+}$to NA (Supplementary Information, Figure 4S). The ground-state conformation depends upon the level of theory employed (Table 2). B3LYP calculations favor binding to the carbonyl oxygen atom over binding to the pyridyl nitrogen atom by $1.5 \mathrm{~kJ} / \mathrm{mol}$, while MP2 theory favors interaction with the pyridyl nitrogen atom over the carbonyl oxygen atom by $7.2 \mathrm{~kJ} / \mathrm{mol}$. Alternatively, when the carboxyl hydrogen atom is oriented toward the pyridyl ring, binding of $\mathrm{Na}^{+}$to both oxygen atoms of the carboxylic acid moiety, forming a stable fourmembered chelation ring, is favored over interaction with the either carbonyl oxygen or pyridyl nitrogen atoms. However, the most favorable four-membered chelation ring conformer lies $5.4 \mathrm{~kJ} / \mathrm{mol}$ in energy above the ground-state conformation. Two low-energy conformers of each type of stable binding mode are found that differ only in the relative orientations of the carboxylic acid moiety and the pyridyl nitrogen atom. In all cases, rotation about the $\mathrm{C}-\mathrm{CO}_{2} \mathrm{H}$ bond results in a small change in the stability of the various $\mathrm{Na}^{+}$binding mode conformers, by 3.5 to $5.4 \mathrm{~kJ} / \mathrm{mol}$.

\section{$\mathrm{Na}^{+}$(Quinoline)}

The calculations find only one favorable binding mode for $\mathrm{Na}^{+}$to Q (Supplementary Information, Figure 4S). In the ground-state conformation, $\mathrm{Na}^{+}$binds to the pyridyl nitrogen atom and lies in the plane of the aromatic ring. A stable cation- $\pi$ binding conformer is also found where $\mathrm{Na}^{+}$sits above the phenyl ring and interacts with the $\pi$ electron density. However, this conformer is less stable than the ground-state conformation by $45.4 \mathrm{~kJ} / \mathrm{mol}$. Attempts to calculate a stable cation- $\pi$ binding conformer in which $\mathrm{Na}^{+}$interacts with the $\pi$ electron density of the pyridyl ring always converged to the ground-state conformation.

\section{$\mathrm{Na}^{+}$(3-Aminoquinoline)}

The calculations find only one favorable binding mode for $\mathrm{Na}^{+}$to AQ (Supplementary Information, Figure 4S). As found for the $\mathrm{Na}^{+}(\mathrm{Q})$ complex, in the ground-state conformation, $\mathrm{Na}^{+}$binds to the pyridyl nitrogen atom and lies in the plane of the aromatic ring. A stable cation- $\pi$ binding conformer is also found in which $\mathrm{Na}^{+}$sits above the phenyl ring and interacts with the $\pi$ electron density analogous to that found for the $\mathrm{Na}^{+}(\mathrm{Q})$ complex. The 3-amino substituent enhances the $\pi$ electron density of the aromatic system such that this conformer becomes more favorable relative to that found for Q, and only lies $29.3 \mathrm{~kJ} / \mathrm{mol}$ in energy above the ground-state conformation. A second stable cation- $\pi$ binding conformer is also found in which $\mathrm{Na}^{+}$interacts with the $\pi$ electron density above the $\mathrm{C}-\mathrm{NH}_{2}$ bond. However, this conformer is less stable than the ground-state conformation by $45.3 \mathrm{~kJ} / \mathrm{mol}$.

Table 2. Measured and Calculated Enthalpies of Sodium Cation Binding to MALDI Matrices at $0 \mathrm{~K}$ in $\mathrm{kJ} / \mathrm{mol}$

\begin{tabular}{|c|c|c|c|c|c|c|c|}
\hline \multirow[t]{3}{*}{ Complex } & \multicolumn{2}{|c|}{ Experiment } & \multirow[t]{3}{*}{ Conformer } & \multicolumn{4}{|c|}{ Theory } \\
\hline & \multirow[t]{2}{*}{$\mathrm{TCID}^{\mathrm{a}}$} & \multirow[t]{2}{*}{$\mathrm{CTRK}^{\mathrm{b}}$} & & \multicolumn{2}{|c|}{$\mathrm{MP} 2^{\mathrm{c}}$} & \multicolumn{2}{|c|}{ B3LYP ${ }^{d}$} \\
\hline & & & & $\mathrm{D}_{0}{ }^{\mathrm{e}}$ & $\mathrm{D}_{0, \mathrm{BSSE}}^{\mathrm{f}}$ & $\mathrm{D}_{0}{ }^{\mathrm{e}}$ & $D_{0, B_{S S E}}{ }^{f}$ \\
\hline \multirow[t]{6}{*}{$\mathrm{Na}^{+}(\mathrm{NA})$} & $125.0(2.9)$ & $192(4)$ & A & 113.9 & 106.8 & 125.4 & 123.0 \\
\hline & & & B & 121.1 & 114.3 & 123.9 & 121.7 \\
\hline & & & $\mathrm{C}$ & 118.1 & 111.3 & 120.4 & 118.2 \\
\hline & & & D & 111.3 & 103.2 & 120.0 & 117.4 \\
\hline & & & $\mathrm{E}$ & 107.9 & 100.6 & 120.0 & 117.4 \\
\hline & & & $\mathrm{F}$ & 107.7 & 99.8 & 116.5 & 114.0 \\
\hline $\mathrm{Na}^{+}(\mathrm{Q})$ & $142.6(3.9)$ & & & 133.9 & 126.3 & 140.5 & 138.2 \\
\hline $\mathrm{Na}^{+}(\mathrm{AQ})$ & $147.0(5.3)$ & $170(5)$ & & 142.3 & 134.6 & 147.5 & 145.1 \\
\hline $\mathrm{Na}^{+}$(PNA) & $162.0(5.0)$ & $181(5)$ & & 164.1 & 156.2 & 188.6 & 186.1 \\
\hline $\mathrm{Na}^{+}$(HPA) & $170.7(5.5)$ & $192(4)$ & & 150.6 & 140.5 & 158.7 & 155.7 \\
\hline $\mathrm{Na}^{+}(\mathrm{PA})$ & $174.1(4.7)$ & & & 175.8 & 165.8 & 183.1 & 180.1 \\
\hline AEU/MAD & $4.6(1.0)$ & $33(23)$ & & $8.1(6.9)$ & $15.2(8.7)$ & $8.4(10.1)$ & $8.9(8.9)$ \\
\hline
\end{tabular}

\footnotetext{
${ }^{a}$ Present results, threshold collision-induced dissociation.

${ }^{\mathrm{b}}$ Cation transfer equilibria and reaction kinetics, reference 52 and converted to $0 \mathrm{~K}$ BDEs using thermal corrections determined here.

${ }^{\mathrm{c}}$ Calculated at the MP2(full)/6-311+G(2d,2p)//B3LYP/6-31 G* levels of theory.

${ }^{d}$ Calculated at the B3LYP/6-311+G(2d,2p)//B3LYP/6-31 G* level of theory.

${ }^{\mathrm{e}}$ Including ZPE corrections with the B3LYP/6-31 G* frequencies scaled by 0.9804 .

${ }^{\mathrm{f}}$ Also includes BSSE corrections.
} 


\section{$\mathrm{Na}^{+}$(Paranitroaniline)}

The calculations find only one favorable binding mode for $\mathrm{Na}^{+}$to PNA (Supplementary Information, Figure 4S). In the ground-state conformation, $\mathrm{Na}^{+}$binds to both oxygen atoms of the nitro substituent and lies in the plane of the aromatic ring. Two stable cation- $\pi$ binding conformers are also found. Binding of $\mathrm{Na}^{+}$to the $\pi$ electron density above the aromatic ring or above the $\mathrm{C}-\mathrm{NH}_{2}$ bond is much less favorable, such that these conformers are less stable than the ground-state conformation by 117.3 and $120.1 \mathrm{~kJ} / \mathrm{mol}$, respectively.

\section{$\mathrm{Na}^{+}$(Picolinic Acid)}

The calculations find only one very favorable binding mode for $\mathrm{Na}^{+}$to PA (Supplementary Information Figure 4S). In the ground-state conformation $\mathrm{Na}^{+}$binds to the carbonyl oxygen and pyridyl nitrogen atoms, forming a stable fivemembered chelation ring. In the next most favorable conformation, $\mathrm{Na}^{+}$binds to the lone pairs of the hydroxyl oxygen and pyridyl nitrogen atoms, again forming a stable five-membered chelation ring. However, binding to the hydroxyl oxygen is less favorable than to the carbonyl oxygen atom and results in this conformation being $33.0 \mathrm{~kJ} / \mathrm{mol}$ less stable than the ground-state conformation. Another stable $\mathrm{Na}^{+}$ binding mode is found when the hydroxyl hydrogen atom of the carboxylic acid moiety is oriented toward the pyridyl ring and $\mathrm{Na}^{+}$binds to both oxygen atoms of the carboxylic acid moiety. Two such conformers are found that lie 20.5 and $72.9 \mathrm{~kJ} / \mathrm{mol}$ in energy above the ground-state conformation, indicating that the hydrogen bonding interaction between the pyridyl nitrogen and hydroxyl hydrogen atoms in the former provides $52.4 \mathrm{~kJ} / \mathrm{mol}$ of stabilization. Stable conformations involving monodentate binding to the carbonyl or hydroxyl oxygen atoms are also possible. However, these conformers are less favorable than the ground-state conformation by more than $68.4 \mathrm{~kJ} / \mathrm{mol}$.

\section{$\mathrm{Na}^{+}$(3-Hydroxypicolinic Acid)}

The calculations find numerous stable, but only one very favorable binding mode for $\mathrm{Na}^{+}$to HPA (Supplementary Information Figure 4S). In the ground-state conformation $\mathrm{Na}^{+}$ binds to the carbonyl oxygen and pyridyl nitrogen atoms, forming a stable five-membered chelation ring that is further stabilized by a hydrogen bond between the hydroxyl oxygen atom of the carboxylic acid moiety and the 3-hydroxyl hydrogen atom. Rotation about the $\mathrm{C}-\mathrm{OH}$ bonds produces two additional stable conformers that lie 14.0 and $14.8 \mathrm{~kJ} / \mathrm{mol}$ higher in energy. In the next most stable binding mode, the hydroxyl hydrogen atom of the carboxylic acid moiety is oriented toward the pyridyl ring, and $\mathrm{Na}^{+}$binds to both oxygen atoms of the carboxylic acid moiety, forming a stable four-membered chelation ring that is further stabilized by two hydrogen bonding interactions; one between the pyridyl nitrogen atom and the hydroxyl hydrogen atom of the carboxylic acid moiety and the other between the carbonyl oxygen and 3-hydroxyl hydrogen atoms. Even with the chelation interaction and two stable hydrogen bonding interactions, this conformation is still $12.9 \mathrm{~kJ} / \mathrm{mol}$ less favorable than the ground-state conformation. Rotation about the $\mathrm{C}-\mathrm{OH}$ bond of the 3-hydroxyl group breaks one of the hydrogen bonds and produces another conformer that is $28.8 \mathrm{~kJ} / \mathrm{mol}$ less stable than the ground-state conformation. A further rotation about the $\mathrm{C}-\mathrm{CO}_{2} \mathrm{H}$ bond breaks the hydrogen bonding interaction between the pyridyl nitrogen and hydroxyl hydrogen atoms, while simultaneously allowing formation of a hydrogen bond between the 3-hydroxyl oxygen atom and the carboxyl hydrogen atom. Clearly, the latter hydrogen bonding interaction is less favorable as the resulting conformer lies $49.4 \mathrm{~kJ} / \mathrm{mol}$ higher in energy than the ground-state conformation. The next most stable binding mode involves $\mathrm{Na}^{+}$binding to the pyridyl nitrogen atom and the carboxyl oxygen atom of the carboxylic acid moiety, again forming a stable fivemembered chelation ring that is further stabilized by a hydrogen bond between the carbonyl oxygen and the 3hydroxyl hydrogen atom. This conformation is $18.4 \mathrm{~kJ} / \mathrm{mol}$ less stable than the ground-state conformation. The final stable $\mathrm{Na}^{+}$binding mode involves $\mathrm{Na}^{+}$interacting with the carbonyl and 3-hydroxyl oxygen atoms forming a stable six-membered chelation ring. Two such conformers are found that are less stable than the ground-state conformation by 24.5 and $45.9 \mathrm{~kJ} /$ $\mathrm{mol}$, indicating that the weak hydrogen bonding interaction between the pyridyl nitrogen and hydroxyl hydrogen atoms in the former stabilizes this conformation by $21.4 \mathrm{~kJ} / \mathrm{mol}$. Again, stable conformations involving monodentate binding to the carbonyl or hydroxyl oxygen atoms are also possible. However, these binding modes are again much less favorable than the nine conformers discussed.

\section{Discussion}

\section{Comparison of Theoretical and Experimental Results}

The measured BDEs of the $\mathrm{Na}^{+}$(MALDI) complexes at $0 \mathrm{~K}$ are summarized in Table 2 along with corresponding theoretical BDEs calculated at the B3LYP/6311+G(2d,2p) and MP2(full) $6-311+G(2 d, 2 p)$ levels of theory. The agreement between B3LYP theory and the experimental results is illustrated in Figure 4a, while the MP2 theory and measured values are compared in Figure 4b. The theoretical calculations suggest that multiple low-energy conformers of the $\mathrm{Na}^{+}$(MALDI) complexes exist. The complexes that may be formed in a measurable population under the experimental conditions employed (i.e., those within $\sim 10 \mathrm{~kJ} / \mathrm{mol}$ of the ground-state conformation) are included in Table 2. Gas phase association of $\mathrm{Na}^{+}$and the MALDI matrix facilitates the interconversion of these low-energy conformers by providing the energy associated with the complexation (123.0 to $200.8 \mathrm{~kJ} / \mathrm{mol}$ at the B3LYP level of theory). Therefore, the ion beams generated in our flow tube ion source 
(a)

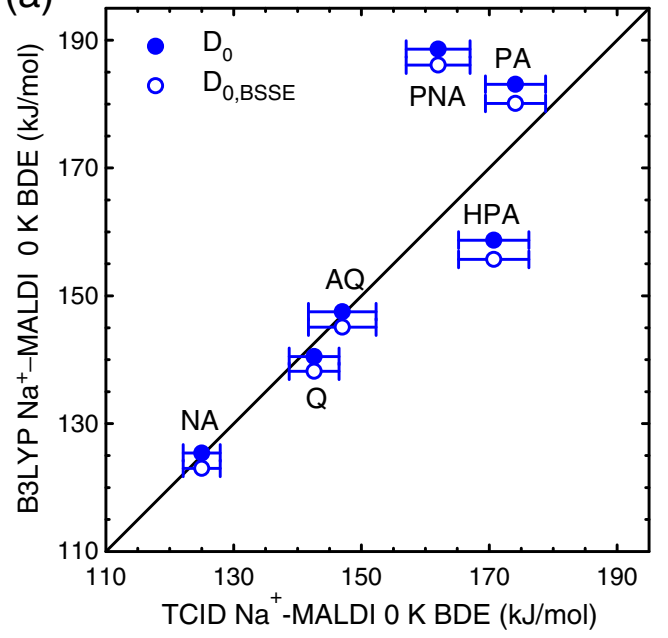

(b)

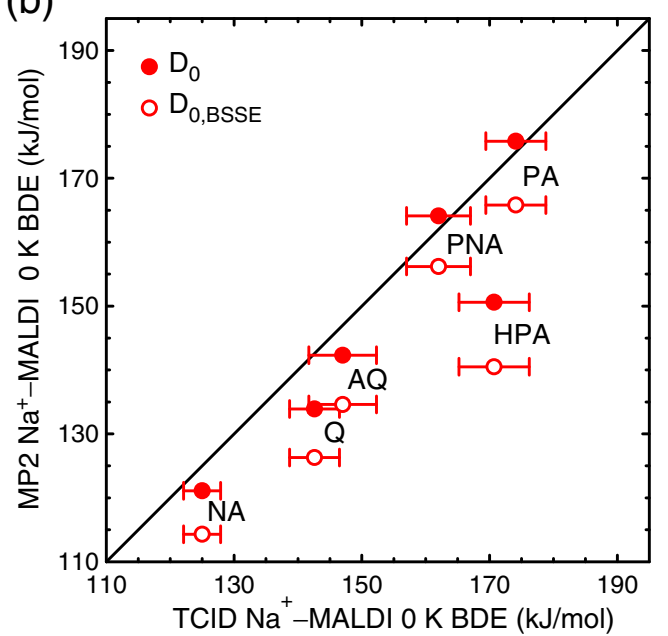

Figure 4. Theoretical $B 3 L Y P / 6-311+G(2 d, 2 p)$ versus experimental TCID $\mathrm{Na}^{+}-\mathrm{MALDI}$ BDEs (a). Theoretical MP2(full)/6-311+G(2d,2p) versus experimental $\mathrm{Na}^{+}-\mathrm{MALDI}$ BDEs (b). All values are at $0 \mathrm{~K}$ and are taken from Table 2. The diagonal lines indicate the values for which calculated and measured BDEs are equal

may consist of mixtures of these low-energy conformers. The thermalization of these complexes via the $\mathrm{He}$ and $\mathrm{Ar}$ bath gases should provide a Maxwell Boltzmann distribution of these species. Therefore, the BDEs measured in our experiments should correspond to the most weakly bound species present in reasonable abundance (at least a few percent) or within $\sim 10 \mathrm{~kJ} /$ mol of the ground-state conformation.

As can be seen in Figure 4a, the agreement between B3LYP theory and experiment is excellent for several complexes, but lies outside of the experimental uncertainty for several complexes. The mean absolute deviation (MAD) between the experimental BDEs and the ground-state conformations calculated using B3LYP theory and including only ZPE corrections for all six $\mathrm{Na}^{+}$(MALDI) complexes is $8.4 \pm 10.1 \mathrm{~kJ} / \mathrm{mol}$, and degrades slightly to $8.9 \pm 8.9 \mathrm{~kJ} / \mathrm{mol}$ when BSSE corrections are also included. These MADs are slightly higher than the average experimental uncertainty (AEU) of $4.6 \pm 1.0 \mathrm{~kJ} / \mathrm{mol}$. The MAD between MP2 theory and the experimental BDEs is $8.1 \pm 6.9 \mathrm{~kJ} / \mathrm{mol}$ including only ZPE corrections, but becomes much poorer when BSSE corrections are included, $15.2 \pm 8.7 \mathrm{~kJ} / \mathrm{mol}$. It has previously been suggested that BSSE corrections overestimate the effects associated with the differing sizes of the basis sets used to calculate the complexes versus the dissociated products and this can lead to binding energies that are too low particularly for MP2 theory [78]. The present results again suggest that the BSSE corrections are too large for MP2 theory. As can be seen in Figure 5, a linear correlation between the B3LYP and MP2 calculated $\mathrm{Na}^{+}-$MALDI BDEs is found. The $\mathrm{Na}^{+}-$MALDI BDEs computed using MP2 theory are systematically lower than BDEs obtained using the B3LYP theory, by $16.3 \pm 7.0 \mathrm{~kJ} / \mathrm{mol}$. The $\mathrm{Na}^{+}$-PNA $\mathrm{BDE}$ deviates somewhat from this trend in that B3LYP theory finds a much larger value than MP2, by $29.9 \mathrm{~kJ} / \mathrm{mol}$. When this value is not included, the correlation between the B3LYP and MP2 values improves, with an average deviation between the B3LYP and MP2 values of $13.6 \pm 2.4 \mathrm{~kJ} / \mathrm{mol}$. In addition, the ground-state conformation found for the $\mathrm{Na}^{+}(\mathrm{NA})$ complex differs between MP2 and B3LYP. The robustness of the theoretical values is not entirely clear, as B3LYP performs better for the complexes to NA, Q, and AQ, while MP2 provides better agreement for the complexes to PNA and PA, and both theories underestimate the binding to HPA.

\section{Comparison to Literature Values}

We compare our results to those of Zenobi and coworkers $[51,52]$, who measured the gas phase $\mathrm{Na}^{+}$basicities $\left(\mathrm{GNa}^{+} \mathrm{Bs}\right)$ of various MALDI matrices including four of the MALDI

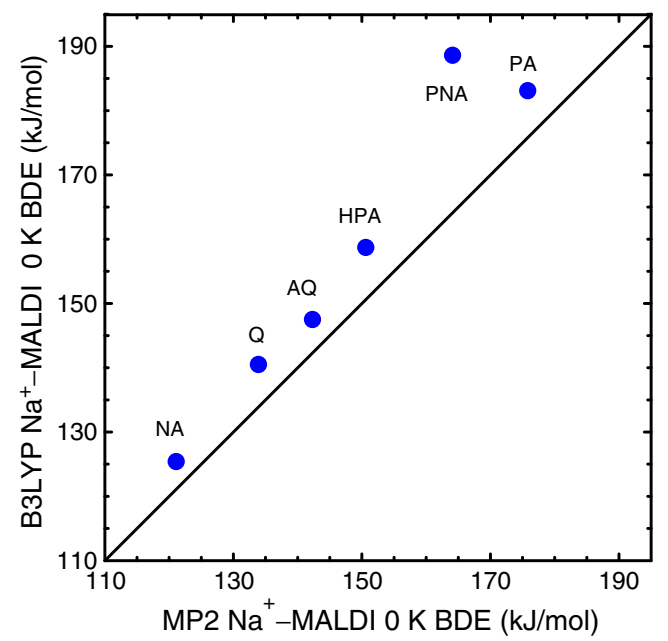

Figure 5. Theoretical MP2(full)/6-311+G(2d,2p) versus theoretical B3LYP/6-311+G(2d,2p) Na+-MALDI BDEs (in kJ/ $\mathrm{mol})$. All values are at $0 \mathrm{~K}$ include ZPE corrections, but do not include BSSE corrections, and are taken from Table 2. The diagonal line indicates the values for which B3LYP and MP2(full) BDEs are equal 
matrices examined here using equilibrium and reaction kinetic methods in a Fourier transform ion cyclotron resonance mass spectrometer (FT-ICR MS). They suggested that the most reliable measurements correspond to the reaction kinetics results because competing reactions that occur under equilibrium conditions complicate the analysis, making it difficult to extract the equilibrium constants directly. To compare their results with those obtained in the present study, their reported gas phase $\mathrm{Na}^{+}$basicities are converted to $0 \mathrm{~K}$ sodium cation affinities or $\mathrm{Na}^{+}$-MALDI BDEs using thermal corrections determined here, and are listed in Table 2 along with our experimental and theoretical values. As can be seen in Table 2, the values measured by Zenobi and coworkers are considerably higher than the threshold CID (TCID) values determined here, and are clearly out of the range of the combined experimental errors in these measurements. The reasons for these discrepancies are not clear. Similar discrepancies were previously found between their reaction kinetics results and our TCID measurements for the complex of $\mathrm{Na}^{+}$to 2,5-dihydroxybenzoic acid (25DHBA). Zenobi and coworkers suggested that the difference may be the result of their experiments probing the diabatic dissociation of the complex (i.e., dissociation without any change in conformation of the matrix). However, adiabatic values are of interest, and TCID methods have been shown to provide adiabatic results. While Zenobi's suggestion may apply to the $\mathrm{Na}^{+}$(DHBA) complex, it cannot apply to the systems investigated here because AQ, PNA, and HPA do not undergo a change in conformation from the neutral MALDI matrix to the $\mathrm{Na}^{+}$(MALDI) complex. Likewise, diabatic dissociation in the reaction kinetics studies cannot explain the difference for NA as the adiabatic and diabatic dissociation energies of this complex differ by only $1.1 \mathrm{~kJ} / \mathrm{mol}$, whereas the TCID and reaction kinetics results differ by $67.0 \mathrm{~kJ} / \mathrm{mol}$ ! Based on these comparisons, and the much better agreement between theory and experiment found for the TCID values, it seems likely that there was some systematic bias that influenced the reaction kinetics measurement in their work, and that the $\mathrm{Na}^{+}$-MALDI BDEs reported here are more reliable.

\section{Insight into MALDI Mass Spectra}

The thermochemical data provided here should be useful for understanding MALDI ionization processes and allow rational approaches to the optimization of MALDI analyses. The matrices studied here exhibit different behavior in the binding of sodium cations. The thermodynamic data determined here is important for selecting a desired matrix for a particular analyte such that the adverse effects of cationization can be minimized and advantages maximized. Among the matrices studied here, NA exhibits the lowest affinity for $\mathrm{Na}^{+}$. Therefore, NA could be a good candidate matrix for analyses where cationization of the analyte is desired (e.g., synthetic polymer analyses). In contrast, high affinity matrices such as PA and HPA could be used to reduce or even eliminate cationization of the analyte, and thereby simplify the observed MALDI mass spectra.

Our theoretical results may also help to improve the understanding of the ionization mechanisms that occur in MALDI. As described by Zenobi and Knochenmuss [24], the ortho-hydroxy carbonyl structural unit is an essential feature of many MALDI matrices that undergo ionization via an excited state proton transfer mechanism. Derivatization of the ortho-hydroxy group by methylation (thus eliminating the hydrogen atom) has proven to strongly degrade MALDI ionization efficiency for some matrices. Therefore, the orthohydroxyl group, which can form intramolecular hydrogen bonds, is an essential feature for an excited state proton transfer mechanism. Among the matrices studied here, the structural features of PA and HPA should allow the excited state proton transfer ionization pathway to occur. In PA and HPA, the carboxyl hydrogen atom engages in an intramolecular hydrogen bond with the pyridyl nitrogen atom. The most stable sodium bound complex of both PA and HPA involves the five-membered ring formation with the pyridyl nitrogen and carbonyl oxygen atoms. To form these complexes, the hydrogen bond between the carboxyl hydrogen and pyridyl nitrogen atoms must be broken. Therefore, binding of $\mathrm{Na}^{+}$to PA and HPA may block its ability to promote excited state proton transfer ionization. This could be used to advantage if ionization other than protonation is desired. Metal cationization may also alter the UV absorption profile of the matrix. This may cause the UV absorption profile to red/blue shift or increase/reduce absorptivity. In addition, the presence of multiple low-energy conformers for the $\mathrm{Na}^{+}$(MALDI) complexes that bind $\mathrm{Na}^{+}$in different fashions may result in multiple ionization pathways for the same matrices leading to more complicated mass spectra.

\section{Conclusions}

The kinetic energy dependence of the CID of $\mathrm{Na}^{+}$(MALDI) complexes, where the MALDI examined include nicotinic acid (NA), quinoline $(\mathrm{Q}), 3$-aminoquinoline $(\mathrm{AQ})$, 4-nitroaniline (PNA), picolinic acid (PA), and 3-hydroxypicolinic acid, (HPA), with $\mathrm{Xe}$ is examined in a guided ion beam tandem mass spectrometer. The dominant dissociation pathway for all complexes is loss of the intact MALDI matrix. Thresholds for these processes are determined after consideration of the effects of the reactant kinetic and internal energy distributions, multiple collisions with Xe, and the dissociation lifetime of the collisionally activated complexes. Details of the ground-state and stable low-energy structures of the neutral MALDI matrices and $\mathrm{Na}^{+}$(MALDI) complexes are determined from theoretical calculations at the B3LYP/6-311+G(2d,2p)//B3LYP/6-31 $\mathrm{G}^{*}$ and MP2(full)/6-311+G(2d,2p)//B3LYP/6-31 G* levels of theory. Very good agreement between the B3LYP calculated and experimentally determined BDEs is found in most cases. The agreement between MP2 theory and experiment is not quite as good as that found for the B3LYP results, but is very good 
when BSSE corrections are ignored. The various binding modes, orientations of the functional groups, $\pi$ electron delocalization, and the polarizability of the neutral MALDI matrices are key factors in determining the strength of $\mathrm{Na}^{+}$ binding in these complexes. The present results suggest that the binding in these $\mathrm{Na}^{+}$(MALDI) complexes is primarily electrostatic, as only simple CID resulting in loss of the intact MALDI matrix is observed. The stability of these $\mathrm{Na}$ ${ }^{+}$(MALDI) complexes is strongly influenced by the mode of binding and the formation of intramolecular hydrogen bonds. The BDEs measured here for the $\mathrm{Na}^{+}$(MALDI) complexes provide valuable information that expands the sodium cation affinity scale and broadens our knowledge of the behavior of MALDI matrices in gas-phase ionization processes.

\section{Acknowledgments}

The authors gratefully acknowledge support for this work by the National Science Foundation (grant CHE-0911191). The authors also thank WSU C\&IT for computer time and support.

\section{References}

1. Rashidzadeh, H., Wang, W., Guo, B.: Matrix Effects on Selectivities of Poly(ethylene glycol)s for Alkali Metal Ion Complexation in MatrixAssisted Laser Desorption/Ionization. Rapid Commun. Mass Spectrom. 14, 439-443 (2000)

2. Chen, R., Yalcin, T., Wallace, W.E., Guttman, M., Li, L.: Laser Desorption Ionization and MALDI Time-of-Flight Mass Spectrometry for Low Molecular Mass Polyethylene Analysis. J. Am. Soc. Mass Spectrom. 12, 1186-1192 (2001)

3. Nielen, M.W.F.: Maldi Time-of-Flight Mass Spectrometry of Synthetic Polymers. Mass Spectrom. Rev. 18, 309-344 (1999)

4. Deery, M.J., Jennings, K.R., Jasieczek, B.C., Haddleton, D.M., Jackson, A.T., Yates, H.T., Scrivens, J.H.: A Study of Cation Attachment to Polystyrene by Means of Matrix-Assisted Laser Desorption/Ionization and Electrospray Ionization-Mass Spectrometry. Rapid Commun. Mass Spectrom. 11, 57-62 (1997)

5. Gidden, J., Wyttenbach, T., Batka, J.J., Weis, P., Jackson, A.T., Scrivens, J.H., Bowers, M.T.: Poly(ethylene terephthalate) Oligomers Cationized by Alkali Ions: Structures, Energetics, and Their Effect on Mass Spectra and the Matrix-Assisted Laser Desorption/Ionization Process. J. Am. Soc. Mass Spectrom. 10, 883-895 (1999)

6. Wang, Y., Rashidzadeh, H., Guo, B.: Structural Effects on Polyether Cationization by Alkali Metal Ions in Matrix-Assisted Laser Desorption/Ionization. J. Am. Soc. Mass Spectrom. 11, 639-643 (2000)

7. Rashidzadeh, H., Guo, B.: Investigation of Metal Attachment to Polystyrenes in Matrix-Assisted Laser Desorption Ionization. J. Am. Soc. Mass Spectrom. 9, 724-730 (1998)

8. Murgasova, R., Hercules, D.M.: MALDI of Synthetic Polymers-an Update. Int. J. Mass Spectrom. 226, 151-162 (2003)

9. Rashidzadeh, H., Hung, H., Guo, B.: Probing Polystyrene Cationization in Matrix-Assisted Laser Desorption/Ionization. Eur. Mass Spectrom. 4, 429-433 (1998)

10. Knochenmuss, R., Lehmann, E., Zenobi, R.: Polymer Cationization in Matrix-Assisted Laser Desorption/Ionization. Eur. Mass Spectrom. 4, 421-427 (1998)

11. Mowat, I.A., Donovan, R.J., Maier, R.R.J.: Enhanced Cationization of Polymers Using Delayed Ion Extraction with Matrix-Assisted Laser Desorption/Ionization. Rapid Commun. Mass Spectrom. 11, 89-98 (1997)

12. Ehlers, A.W., de Koster, C.E., Meier, R.J., Lammertsma, K.: MALDITOF-MS of Saturated Polyolefins by Coordination of Metal Cations: A Theoretical Study. J. Phys. Chem. A 105, 8691-8695 (2001)

13. Fati, D., Leeman, V., Vasil'ev, Y.V., Drewello, T., Leyh, B., Hungerbühler, H.: Alkali Cation Attachment to Derivatized Fullerenes Studied by Matrix-
Assisted Laser Desorption/Ionization. J. Am. Soc. Mass Spectrom. 13, $1448-1458$ (2002)

14. Xu, S., Li, Y., Zou, H., Qiu, J., Guo, Z., Guo, B.: Carbon Nanotubes as Assisted Matrix for Laser Desorption/Ionization Time-of-Flight Mass Spectrometry. Anal. Chem. 75, 6191-6195 (2003)

15. Blais, J.C., Turrin, C.O., Caminade, A.M., Majoral, J.P.: MALDI TOF Mass Spectrometry for the Characterization of Phosphorus-Containing Dendrimers. Scope and Limitations. Anal. Chem. 72, 5097-5105 (2000)

16. Chessa, G., Scrivanti, A., Seraglia, R., Traldi, P.: Matrix Effects on Matrix-Assisted Laser Desorption/Ionization Mass Spectrometry Analysis of Dendrimers with a Pyridine-Based Skeleton. Rapid Commun. Mass Spectrom. 12, 1533-1537 (1998)

17. Puapaiboon, U., Taylor, R.T.: Characterization and Monitoring Reaction of Polyurethane Dendritic Wedges and Dendrimers Using MatrixAssisted Laser Desorption/Ionization Time-of-Flight Mass Spectrometry. Rapid Commun. Mass Spectrom. 13, 508-515 (1999)

18. Chiarelli, M.P., Sharkey, A.G., Hercules, D.M.: Excited-State Proton Transfer in Laser Mass Spectrometry. Anal. Chem. 65, 307-311 (1993)

19. Karas, M., Bahr, U., Giessmann, U.: Matrix-Assisted Laser Desorption Ionization Mass Spectrometry. Mass Spectrom. Rev. 10, 335-357 (1991)

20. Gimon-Kinsel, M., Preston-Schaffter, L.M., Kinsel, G.R., Russell, D. H.: Effects of Matrix Structure/Acidity on Ion Formation in MatrixAssisted Laser Desorption Ionization Mass Spectrometry. J. Am. Chem. Soc. 119, 2534-2540 (1997)

21. Ehring, H., Karas, M., Hillenkamp, F.: Role of Photoionization and Photochemistry in Ionization Processes of Organic Molecules and Relevance for Matrix-Assisted Laser Desorption Ionization Mass Spectrometry. Org. Mass Spectrom. 27, 472-480 (1992)

22. Horneffer, V., Dreisewerd, K., Ludenmann, H.-C., Hillenkamp, F., Lage, M., Strupat, K.: Is the Incorporation of Analytes Into Matrix Crystals a Prerequisite for Matrix-Assisted Laser Desorption/Ionization Mass Spectrometry? A Study of Five Positional Isomers of Dihydroxybenzoic Acid. Int. J. Mass Spectrom. 185/186/187, 859-870 (1999)

23. Liao, P.C., Allison, J.: Ionization processes in matrix-assisted laser desorption/ionization mass spectrometry: Matrix-Dependent Formation of $[\mathrm{M}+\mathrm{H}]^{+}$vs $[\mathrm{M}+\mathrm{Na}]^{+}$Ions of Small Peptides and Some Mechanistic Comments. J. Mass Spectrom. 30, 408-423 (1995)

24. Zenobi, R., Knochenmuss, R.: Ion Formation in MALDI Mass Spectrometry. Mass Spectrom. Rev. 17, 337-366 (1998)

25. Zhang, J., Zenobi, R.: Matrix-Dependent Cationization in MALDI Mass Spectrometry. J. Mass Spectrom. 39, 808-816 (2004)

26. Knochenmuss, R., Dubois, F., Dale, M.J., Zenobi, R.: The Matrix Suppression Effect and Ionization Mechanisms in Matrix-Assisted Laser Desorption/Ionization. Rapid Commun. Mass Spectrom. 10, 871-877 (1996)

27. Botek, E., Debrun, J.L., Hakim, B., Morin-Allory, L.: Attachment of Alkali Cations on $\beta$-D-Glucopyranose: Matrix-Assisted Laser Desorption/Ionization Time-of-Flight Studies and ab initio Calculations. Rapid Commun. Mass Spectrom. 15, 273-276 (2001)

28. Scrivens, J.H., Jackson, A.T., Yates, H.T., Green, M.R., Critchley, G., Brown, J., Bateman, R.H., Bowers, M.T., Gidden, J.: The Effect of the Variation of Cation in the Matrix-Assisted Laser Desorption/IonizationCollision Induced Dissociation (MALDI-CID) Spectra of Oligomeric Systems. Int. J. Mass Spectrom. Ion Processes 165/166, 363-375 (1997)

29. Smirnow, I.P., Zhu, X., Taylor, T., Huang, Y., Ross, P., Papayanopoulos, I. A., Martin, S.A., Pappin, D.J.: Suppression of $\alpha$-Cyano-4-hydroxycinnamic Acid Matrix Clusters and Reduction of Chemical Noise in MALDITOF Mass Spectrometry. Anal. Chem. 76, 2958-2965 (2004)

30. Chen, W., Chen, Y.: Reducing the Alkali Cation Adductions of Oligonucleotides Using Sol-Gel-Assisted Laser Desorption/Ionization Mass Spectrometry. Anal. Chem. 75, 4223-4228 (2003)

31. North, S., Okafo, G., Birrell, H., Haskins, N., Camilleri, P.: Minimizing Cationization Effects in the Analysis of Complex Mixtures of Oligosaccharides. Rapid Commun. Mass Spectrom. 11, 1635-1642 (1997)

32. Dogruel, D., Nelson, R.W., Williams, P.: The Effects of Matrix pH and Cation Availability on the Matrix-assisted Laser Desorption/Ionization Mass Spectrometry of Poly(methyl methacrylate). Rapid Commun. Mass Spectrom. 10, 801-804 (1996)

33. Jackson, A.T., Yates, H.T., MacDonald, W.A., Scrivens, J.H., Critchley, G., Brown, J., Deery, M.J., Jennings, K.R., Brookes, C.: Time-Lag Focusing and Cation Attachment in the Analysis of Synthetic Polymers 
by Matrix-Assisted Laser Desorption/Ionization-Time-of-Flight-Mass Spectrometry. J. Am. Soc. Mass Spectrom. 8, 32-139 (1997)

34. Shields, S.J., Bluhm, B.K., Russel, D.H.: Novel Method for $[\mathrm{M}+\mathrm{Cu}]^{+}$ Ion Formation by Matrix-Assisted Laser Desorption Ionization. Int. J. Mass Spectrom. 182/183, 185-195 (1999)

35. Keki, S., Deak, G., Zsuga, M.: Copper(I) Chloride: a Simple Salt for Enhancement of Polystyrene Cationization in Matrix-Assisted Laser Desorption/Ionization Mass Spectrometry. Rapid Commun. Mass Spectrom. 15, 675-678 (2001)

36. Cohen, S.L., Chait, B.T.: Influence of Matrix Solution Conditions on the MALDI-MS Analysis of Peptides and Proteins. Anal. Chem. 68, 3137 (1996)

37. Zhang, N., Doucette, A., Li, L.: Two-Layer Sample Preparation Method for MALDI Mass Spectrometric Analysis of Protein and Peptide Samples Containing Sodium Dodecyl Sulfate. Anal. Chem. 73, 2968$2975(2001)$

38. Mank, M., Stahl, B., Boehm, G.: 2,5-Dihydroxybenzoic Acid Butylamine and Other Ionic Liquid Matrixes for Enhanced MALDI-MS Analysis of Biomolecules. Anal. Chem. 76, 2938-2950 (2004)

39. Knochenmuss, R., Zenobi, R.: MALDI Ionization: In-Plume Processes. Chem. Rev. 103, 441-452 (2003)

40. Ohanessian, G.: Interaction of MALDI Matrix Molecules with $\mathrm{Na}^{+}$in the Gas Phase. Int. J. Mass Spectrom. 219, 577-592 (2002)

41. Lidgard, R., Duncan, M.W.: Utility of Matrix-Assisted Laser Desorption/Ionization Time-of-Flight Mass Spectrometry for the Analysis of Low Molecular Weight Compounds. Rapid Commun. Mass Spectrom. 9, 128-132 (1995)

42. Bökelmann, V., Spengler, B., Kaufmann, R.: Dynamical Parameters of Ion Ejection and Ion Formation in Matrix-Assisted Laser Desorption/ Ionization. Eur. Mass Spectrom. 1995(1), 81-93 (1995)

43. Bourcier, S., Hoppilliard, Y.: B3LYP DFT Molecular Orbital Approach, an Efficient Method to Evaluate the Thermochemical Properties of MALDI Matrices. Int. J. Mass Spectrom. 217, 231-244 (2002)

44. Burton, R.D., Watson, C.H., Eyler, J.R., Lang, G.L., Powell, D.H., Avery, M.Y.: Proton Affinities of Eight Matrices Used for MatrixAssisted Laser Desorption/Ionization. Rapid Commun. Mass Spectrom. 11, 443-446 (1997)

45. Thomas, J.D.J., Bojesen, G., Rahbek-Nielsen, H.: The Proton Affinities of Seven Matrix-Assisted laser Desoprtion/Ionization Matrices Correlated with the Formation of Multiply Charged Ions. Eur. Mass Spectrom. 4, 39-45 (1998)

46. Mirza, S.P., Raju, N.P., Vairamani, M.: Estimation of the Proton Affinity Values of Fifteen Matrix-Assisted Laser Desorption/Ionisation Matrices Under Electrospray Ionization Conditions Using the Kinetic Method. J. Am. Soc. Mass Spectrom. 15, 431-435 (2004)

47. Steenvoorden, R.J.J.M., Breuker, K., Zenobi, R.: The Gas-Phase Basicities of Matrix-Assisted Laser Desorption/Ionization Matrices. Eur. Mass Spectrom. 3, 339-346 (1997)

48. Breuker, K., Knochenmuss, R., Zenobi, R.: Gas-Phase Basicities of Deprotonated Matrix-Assisted Laser Desorption/Ionization Matrix Molecules. Int. J. Mass Spectrom. 184, 25-38 (1999)

49. Breuker, K., Knochenmuss, R., Zhang, J., Stortelder, A., Zenobi, R.: Thermodynamic Control of Final Ion Distributions in MALDI: In-plume Proton Transfer Reactions. Int. J. Mass Spectrom. 226, 211-222 (2003)

50. Yassin, F.H., Marynick, D.S.: Computational Estimates of the GasPhase Acidities of Dihydroxybenzoic Acid Radical Cations and Their Corresponding Neutral Species. Theochem. 629, 223-235 (2003)

51. Zhang, J., Knochenmuss, R., Stevenson, E., Zenobi, R.: The Gas-Phase Sodium Basicities of Common Matrix-Assisted Laser Desorption/ Ionization Matrices. Int. J. Mass Spectrom. 213, 237-250 (2002)

52. Zhang, J., Ha, T.-K., Knochenmuss, R., Zenobi, R.: Theoretical Calculation of Gas-Phase Sodium Binding Energies of Common MALDI Matrices J. Phys. Chem. A 106, 6610-6617 (2002)

53. Zhang, J., Dyachokva, E., Ha, T.-K., Knochenmuss, R., Zenobi, R.: GasPhase Potassium Binding Energies of MALDI Matrices: An Experimental and Theoretical Study J. Phys. Chem. A 107, 6891-6900 (2003)

54. Chinthaka, S.D.M., Chu, Y., Rannulu, N.S., Rodgers, M.T.: Sodium Cation Affinities of MALDI Matrices Determined by Guided In Beam Tandem Mass Spectrometry: Application to Benzoic Acid Derivatives. J. Phys. Chem. A 110, 1426-1437 (2006)

55. Chinthaka, S.D.M., Rodgers, M.T.: Potassium Cation Affinities of Matrix Assisted Laser Desorption Ionization Matrices Determined by Threshold Collision-Induced Dissociation: Application to Benzoic Acid Derivatives. J. Phys. Chem. A 111, 8152-8162 (2007)
56. Rodgers, M.T.: Substituent Effects in the Binding of Alkali Metal Ions to Pyridines, Studied by Threshold Collision-Induced Dissociation and ab Initio Theory: The Methylpyridines. J. Phys. Chem. A 105, 2374$2383(2001)$

57. Teloy, E., Gerlich, D.: Integral Cross Sections for Ion Molecule Reactions: The Guided Ion Beam Technique. Chem. Phys. 4, 417-427 (1974)

58. Gerlich, D.: Inhomogeneous RF Fields: A Versatile Tool for the Study of Processes with Slow Ions. Diplomarbeit, University of Freiburg, Federal Republic of Germany, 1971.

59. Gerlich, D.: State-Selected and State-to-State Ion-Molecule Reaction Dynamics, Part I, Experiment. In: Ng, C.-Y., Baer, M. (eds.) Advances in Chemical Physics Series, vol. 82, pp. 1-176. Wiley, New York (1992)

60. Ervin, K.M., Armentrout, P.B.: Translational Energy Dependence of Ar++ $\mathrm{XY}(\mathrm{ArX}++\mathrm{Y}(\mathrm{XY}=\mathrm{H} 2, \mathrm{D} 2, \mathrm{HD})$ from Thermal to $30 \mathrm{eV} \mathrm{c.m.} \mathrm{J.} \mathrm{Chem.}$ Phys. 83, 166-189 (1985)

61. Armentrout, P.B.: Not Just a Structural Tool: The Use of Guided Ion Beam Tandem Mass Spectrometry to Determine Thermochemistry. $J$. Am. Soc. Mass Spectrom. 13, 419-434 (2002)

62. Dalleska, N.F., Honma, K., Sunderlin, L.S., Armentrout, P.B.: Solvation of Transition Metal Ions by Water. Sequential Binding Energies of $\mathrm{M}+(\mathrm{H} 2 \mathrm{O}) \mathrm{x}(\mathrm{x}=1-4)$ for $\mathrm{M}=\mathrm{Ti}-\mathrm{Cu}$ Determined by Collision-Induced Dissociation. J. Am. Chem. Soc. 116, 3519-3528 (1994)

63. Schultz, R.H., Armentrout, P.B.: A Guided-Ion Beam Study of the Reactions of $\mathrm{N}_{4}^{+}$with $\mathrm{H}_{2}, \mathrm{HD}$, and $\mathrm{D}_{2}$ : An Evaluation of PseudoArrhenius Analyses of Ion-molecule Reaction Systems. J. Chem. Phys. 96, 1046-1052 (1992)

64. Frisch, M. J., Trucks, G. W., Schlegel, H. B., Scuseria, G. E., Robb, M. A., Cheeseman, J. R., Montgomery, Jr., J. A., Vreven, T., Kudin, K. N., Burant, J. C., Millam, J. M., Iyengar, S. S., Tomasi, J., Barone, V., Mennucci, B., Cossi, M., Scalmani, G., Rega, N., Petersson, G. A., Nakatsuji, H., Hada, M., Ehara, M., Toyota, K., Fukuda, R., Hasegawa, J., Ishida, M., Nakajima, T., Honda, Y., Kitao, O., Nakai, H., Klene, M., Li, X., Knox, J. E., Hratchian, H. P., Cross, J. B., Bakken, V., Adamo, C., Jaramillo, J., Gomperts, R., Stratmann, R. E., Yazyev, O., Austin, A. J., Cammi, R., Pomelli, C., Ochterski, J. W., Ayala, P. Y., Morokuma, K., Voth, G. A., Salvador, P., Dannenberg, J. J., Zakrzewski, V. G., Dapprich, S., Daniels, A. D., Strain, M. C., Farkas, O., Malick, D. K., Rabuck, A. D., Raghavachari, K., Foresman, J. B., Ortiz, J. V., Cui, Q., Baboul, A. G., Clifford, S., Cioslowski, J., Stefanov, B. B., Liu, G. Liashenko, A., Piskorz, P., Komaromi, I., Martin, R. L., Fox, D. J., Keith, T., Al-Laham, M. A., Peng, C. Y., Nanayakkara, A., Challacombe, M., Gill, P. M. W., Johnson, B., Chen, W., Wong, M. W., Gonzalez, C., Pople, J. A.: Gaussian, Inc., Wallingford CT, 2004.

65. Foresman, J. B., Frisch, A. E.: Exploring Chemistry with Electronic Structure Methods $2^{\text {nd }}$ Ed., Gaussian 03, Revision C.02; Gaussion: Pittsburgh, 1996, p. 64.

66. Adamo, C., Barone, V.: Toward Reliable Density Functional Methods Without Adjustable Parameters: The PBE0 Model. J. Chem. Phys. 110, 6158-6169 (1999)

67. Smith, S.M., Markevitch, A.N., Romanov, D.A., Li, X., Levis, R.J., Schlegel, H.B.: Static and Dynamic Polarizabilities of Conjugated Molecules and Their Cations. J. Phys. Chem. A 108, 11063-11072 (2004)

68. Muntean, F., Armentrout, P.B.: Guided Ion Beam Study of CollisionInduced Dissociation Dynamics: Integral and Differential Cross Sections. J. Chem. Phys. 115, 1213-1229 (2001)

69. Beyer, T.S., Swinehart, D.F.: Algorithm 448: Number of Multiplerestricted partitions. Commun. Assoc. Comput. Machines 16, 379 (1973)

70. Stein, S.E., Rabinovitch, B.S.: Accurate Evaluation of Internal Energy Level Sums and Densitites Including Anharmonic Oscillators and Hindered Rotors. J. Chem. Phys. 58, 2438-2445 (1973)

71. Stein, S.E., Rabinovitch, B.S.: On the Use of Exact State Counting Methods in RRKM Rate Calculations. Chem. Phys. Lett. 49, 183-188 (1977)

72. Rodgers, M.T., Ervin, K.M., Armentrout, P.B.: Statistical Modeling of Collision-Induced Dissociation Thresholds. J. Chem. Phys. 106, 44994508 (1997)

73. Khan, F.A., Clemmer, D.E., Schultz, R.H., Armentrout, P.B.: The Sequential Bond Energies of $\mathrm{Cr}(\mathrm{CO})_{x}^{+}, x=1-6$. J. Phys. Chem. 97, 7978-7987 (1993)

74. Chesnavich, W.J., Bowers, M.T.: Theory of Translationally Driven Reactions. J. Phys. Chem. 83, 900-905 (1979) 
75. Armentrout, P.B., Simons, J.: Understanding Heterolytic Bond Cleavage. J. Am. Chem. Soc. 114, 8627-8633 (1992)

76. See for example Figure 1 in Dalleska, N. F., Honma, K., Armentrout, P. B.: Stepwise Solvation Enthalpies of Protonated Water Clusters: Collision Induced Dissociation as an Alternative to Equilibrium Studies. J. Am. Chem. Soc. 115, 12125-12131 (1993)
77. Rodgers, M.T., Armentrout, P.B.: Absolute Binding Energies of Lithium Ions to Short Chain Alcohols, $\mathrm{C}_{n} \mathrm{H}_{n+2} \mathrm{O}, n=1-4$, Determined by Threshold Collision-Induced Dissociation. J. Phys. Chem. A 101, 2614-2625 (1997)

78. Feller, D.: A Complete Basis Set Estimate of Cation- $\pi$ Bond Strengths: $\mathrm{Na}^{+}$(ethylene) and $\mathrm{Na}^{+}$(benzene). Chem. Phys. Lett. 322, 543-548 (2000) 